\title{
Improvement of the Thermal Emissivity Calculated with the Vegetation Cover Method by Using Optical Atmospherically Corrected Images
}

\author{
Lucas Martínez, Vicenç Palà, Roman Arbiol \\ Àrea de teledetecció i procés d'imatge \\ Institut Cartogràfic de Catalunya (ICC) \\ Parc de Montjuïc s/n, 08038 Barcelona, Spain \\ Lucas.Martinez@icc.cat
}

\author{
Vicente Caselles, Enric Valor \\ Departament de Física de la Terra i Termodinàmica \\ Universitat de València (UV) \\ Dr. Moliner, 50, 46100 Burjassot, Spain \\ Vicente.Caselles@uv.es
}

\begin{abstract}
In this paper we assess the influence caused by the lack of atmospheric correction of the optical images used to calculate land surface emissivity (LSE). When thermal emissivity is determined by the Vegetation Cover Method (VCM), information from the solar spectrum in order to calculate the vegetation cover fraction is required. The atmospheric correction is performed in this research by using the combination of the Dark Dense Vegetation method (DDV) and the Second Simulation of the Satellite Signal in the Solar Spectrum (6S) code. The methodology was applied to a Landsat TM image of Tomelloso, Spain. It was determined that the emissivity between 10 and 12 $\mu \mathrm{m}$ only increases $0.4 \%$ (which represents a systematic error of approximately $+0.2 \mathrm{~K}$ in temperature) when atmospherically corrected reflectances are used in relation to non-corrected scenes.
\end{abstract}

Keywords- optical atmospheric correction, thermal emissivity, Vegetation Cover Method, 6S, Dark Dense Vegetation method, Landsat TM.

\section{INTRODUCTION}

The land surface temperature (LST) retrieval by means of passive thermal remote sensing depends on accurate emissivity specification [1]. Land surface emissivity (LSE) measurement by remote sensing has the inconvenience that temperature and emissivity cannot be calculated simultaneously, since the number of unknown variables is always higher than the alone measurements. In order to solve this uncertainty, qualitative approximations are used such as, for instance, supposing a constant value of the emissivity for all the bands, or introducing some hypothesis such as, for example, relating emissivity with some of the vegetation parameters. The Vegetation Cover Method (VCM) developed by [2], is based on the idea suggested by [3] of the dependency between the emissivity in the thermal infrared region and the Normalized Difference Vegetation Index (NDVI). As a consequence, it is expected that the determination of thermal emissivity is affected to a certain extent by the interaction of the atmosphere with the optical solar radiation, which is the scope of this paper.

The atmospheric effect is sometimes not significant [4], but this is not the general case. There are many procedures in the literature for obtaining a reflectance free of atmospheric effects from multispectral satellite sensors. The most accurate are those based on both simultaneous in-field measurements of the atmospheric parameters, like aerosol optical thickness (AOT) in the study area, and the use of a radiative transfer code [5]. In order to do that, one of the most popular codes is the Second Simulation of the Satellite Signal in the Solar Spectrum (6S), described by [6]. Nevertheless, intermediate and more operative solutions may be also adopted, such as the use of an atmospheric normalization method $[7,8]$ or the use of standard climatologic values for the atmospheric parameters [9].

As we previously have mentioned, there are several atmospheric parameters like the AOT to be calculated or measured in order to apply a radiative transfer code. Since a simultaneous AOT measurement is not usually available, there are several methods to determine it by means of only remote sensing imagery. Many works reference the Dark Dense Vegetation (DDV) approximation described in [10] and the Contrast Reduction (CD) from [11]. The former is easier to apply, since the later was designed for a multitemporal case, therefore it requires more than a single image.

The aim of this paper is to measure the influence of solar spectrum atmospheric correction in the estimation of thermal emissivity with VCM method. For this purpose, a combination of the 6S and DDV methods has been used, which proved to be operative and accurate, with no need to use data collected in field campaigns or multitemporal series.

\section{METHODOLOGY}

\section{A. The Vegetation Cover Method}

The VCM is a model for LSE of a pixel that provides the thermal emissivity $\varepsilon$ as the following expression:

$$
\varepsilon=\varepsilon_{v} \cdot P_{V}+\varepsilon_{g} \cdot\left(1-P_{V}\right)+4 \cdot\langle d \varepsilon\rangle \cdot P_{V} \cdot\left(1-P_{V}\right)
$$

where $\varepsilon_{\mathrm{v}}$ represents vegetation emissivity, $\mathrm{P}_{\mathrm{V}}$ is the fractional vegetation cover, $\varepsilon_{\mathrm{g}}$ is bare soil emissivity and $<\mathrm{d} \varepsilon>$ is the cavity term [2]. 
Emissivity values for vegetation and bare soil can be measured in the field [12] or obtained from a database on literature as in [13].

The determination of the fractional vegetation cover is estimated by using the NDVI, using the following expression from [2]

$$
P_{V}=\frac{\left(1-\frac{N D V I}{N D V I_{G}}\right)}{\left(1-\frac{N D V I}{N D V I_{G}}\right)-K \cdot\left(1-\frac{N D V I}{N D V I_{V}}\right)}
$$

where $\mathrm{NDVI}_{\mathrm{G}}$ and $\mathrm{NDVI}_{\mathrm{V}}$ represent the minimal and maximum values of the NDVI image respectively, which, provided that the area is large enough, will correspond with areas with no vegetation (bare soil) and with full vegetation coverage.

The $\mathrm{K}$ parameter for a Landsat TM set of bands is calculated as in [2]

$$
K=\frac{\rho_{4 V}-\rho_{3 V}}{\rho_{4 G}-\rho_{3 G}}
$$

where $\rho_{4 \mathrm{~V}}$ and $\rho_{3 \mathrm{~V}}$ are the reflectances in the near infrared (TM band 4) and in the red (TM band 3 ) for the area with full vegetation cover, $\rho_{4 G}$ and $\rho_{3 G}$ are the reflectances in the near infrared (TM band 4) and in the red (TM band 3) for the area without vegetation (bare soil). In [2] it was reported that the VCM error varies between $0.5 \%$ and $2.0 \%$, depending on that the values used as $\varepsilon_{\mathrm{g}}$ and $\varepsilon_{\mathrm{v}}$ were measured at field or global standard estimations.

\section{B. The DDV and $6 S$ Methods}

The absorption effect of the atmosphere gases, and the dispersion effect of gases and aerosols, is simulated by means of the $6 \mathrm{~S}$ code. The system needs several input parameters in order to characterize the atmosphere. The accuracy of the simulations of $6 \mathrm{~S}$ depends on the likelihood of the atmospheric parameters [6].

The DDV method is based on the use of dark areas with dense vegetation or DDV, thus the signal received by the sensor comes to a great extent from the atmosphere [14]. According to [15], at the bottom of the atmosphere for the DDV areas and using Landsat TM images, the reflectance in the blue $\left(\rho_{b}^{1},\right)$ and the reflectance in the red $\left(\rho^{3}{ }_{b}\right)$ can be calculated from the middle infrared reflectance $\left(\rho^{7}{ }_{b}\right.$ ) by using the following equations:

$$
\rho_{b^{\prime}}^{1}=\frac{\rho_{b^{\prime}}^{7}}{4.3} \quad \rho_{b^{\prime}}^{3}=\frac{\rho_{b^{\prime}}^{7}}{2.0}
$$

The DDV method for the measurement of the AOT is shown graphically in Fig. 1. The following paragraphs describe the process and the relationships between top and bottom of the atmosphere reflectances that result in determining the AOT.

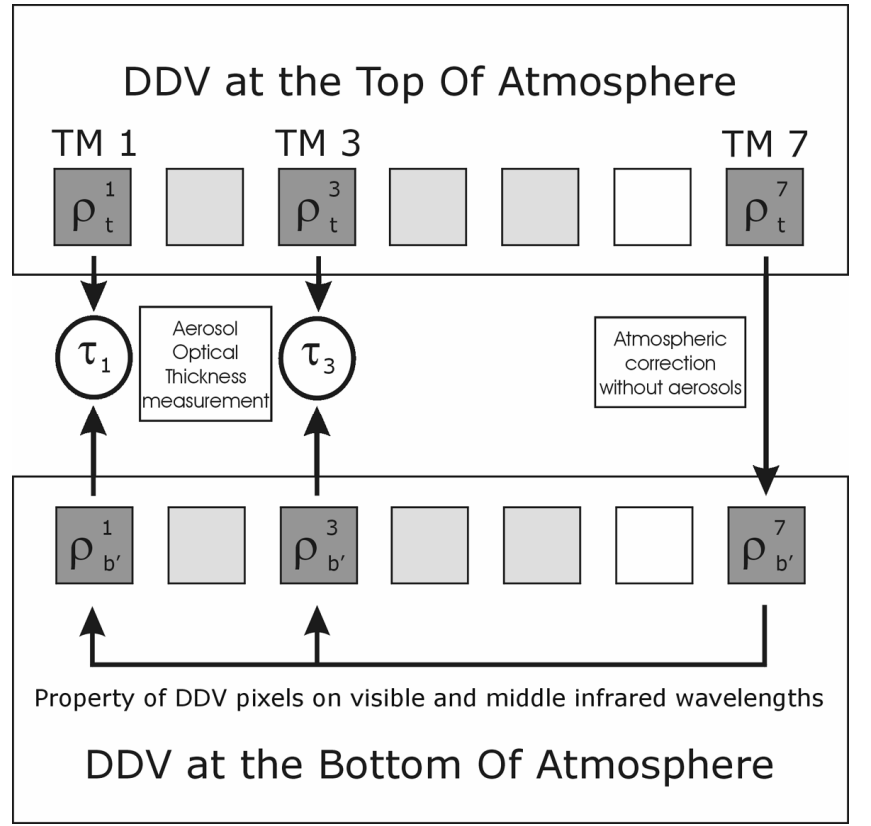

Figure 1. Esqueme of the procedure for the measurement of the aerosol optical depth using the 6S and DDV methods.

-The DDV areas are selected, at the top of the atmosphere image, using a simple reflectance threshold in the middle infrared (TM band 7). Then, a mean value of the reflectance in the middle infrared $\left(\rho_{t}^{7}\right)$ for the selected DDV is calculated.

- The top of the atmosphere reflectance value $\left(\rho_{t}^{7}\right)$ is corrected atmospherically with the $6 \mathrm{~S}$ method using the clean atmosphere hypothesis i.e. with no aerosol, in order to obtain a good estimation of the DDV reflectance at the bottom of the atmosphere for the middle infrared $\left(\rho^{7}{ }_{b}\right)$.

-With the reflectance at the bottom of the atmosphere for the middle infrared $\left(\rho^{7}{ }_{b}\right)$ it becomes possible to estimate the DDV reflectance at the bottom of the atmosphere for the blue and red channels, $\left(\rho^{1}{ }_{b}\right)$ and $\left(\rho^{3}{ }_{b}\right)$, using the equations (4).

- Using the estimation of reflectance at the bottom of the atmosphere for the blue and red channels, $\left(\rho^{1}{ }_{b}\right)$ and $\left(\rho^{3}{ }_{b}\right)$ it is possible to simulate blue and red top of the atmosphere reflectances $\left(\rho^{1}{ }_{t}\right.$ and $\rho^{3}$ ), for a series of aerosol AOT values at $\lambda=550 \mathrm{~nm}$ by means of the $6 \mathrm{~S}$ code.

-With these simulations a table is made for each channel (blue and red), which contains the reflectance at the top of the atmosphere for the DDV areas, with the corresponding aerosol optical thickness at $\lambda=550 \mathrm{~nm}$.

- In the tables previously calculated, the reflectance of the DDV in blue $\left(\rho_{t}^{1}\right)$ and red $\left(\rho_{t}^{3}\right)$ at the top of the atmosphere will be interpolated, thus estimating the aerosol optical thickness at $\lambda=550 \mathrm{~nm}$ from blue and red channels. $\tau_{1}$ will represent the aerosol optical thickness at $\lambda=550 \mathrm{~nm}$ obtained with the blue channel, and $\tau_{3}$ that of the red one. Since $\tau_{1}$ and $\tau_{3}$ are two estimations of the same parameter (AOT at $\lambda=550 \mathrm{~nm}$ ) they are expected to fit. 
Once optical thickness at $\lambda=550 \mathrm{~nm}$ by means of the DDV method is calculated, the next step is to perform the atmospheric correction of the imagery. This is done with the $6 \mathrm{~S}$ method, using the aerosol optical thickness value obtained before.

In [16] it is reported that the accuracy of the DDV method for the measure of the aerosol optical thickness was estimated as $\pm 0.06 \mathrm{~m}^{-1}$. The absolute error of the reflectance calculated using the aforementioned combination of $6 \mathrm{~S}$ and DDV was estimated as \pm 0.015 for visible channels and \pm 0.08 in the near infrared, according to [15].

\section{RESULTS}

We have applied the described methodology to a scene of the Tomelloso area, which is located in the North-eastern end of the province of Ciudad Real (Spain), in the centre of the natural region of La Mancha (Fig. 2). It is a flat area at $670 \mathrm{~m}$ above the sea level. The landscape is arid, with little woodland and vineyard plantations. The climate is Mediterranean with continental features; the mean temperature ranges from $5{ }^{\circ} \mathrm{C}$ to $26{ }^{\circ} \mathrm{C}$, with a mean annual precipitation of $350 \mathrm{~mm}$. In this area, for the interval $10-12 \mu \mathrm{m}$, field measurements yield that $\varepsilon_{\mathrm{g}}=0.975, \varepsilon_{\mathrm{v}}=0.987$ and they estimated the cavity term as $<\mathrm{d} \varepsilon>0.011[17]$.

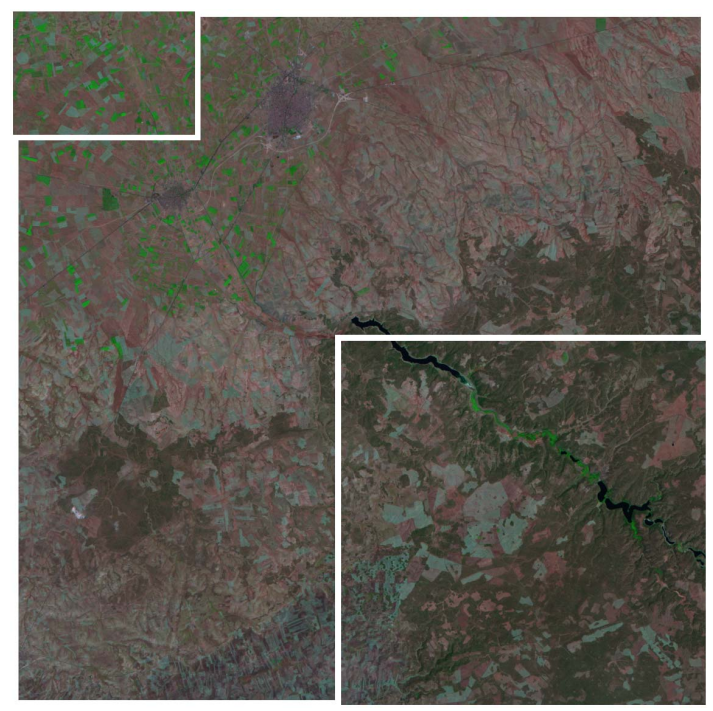

Figure 2. Landsat TM image of the test site (Sub-scene A: upper right corner; Sub-scene B: downer left corner).

We applied the atmospheric correction method proposed to a Landsat 5 TM image sub-scene (1124 by 1124 pixels) taken on August 23, 1994 at 10:05 GMT and centred at geographical coordinates $2.9195 \mathrm{~W}$ and $39.1256 \mathrm{~N}$. First of all, the DDV regions in the image were selected using a reflectance threshold of 0.1 in the middle infrared top of the atmosphere reflectance. The mean reflectances and the standard deviations for the whole set of selected DDV areas at the top of the atmosphere were $\rho_{\mathrm{t}}^{7}=0.088 \pm 0.006\left(\mathrm{TM} 7\right.$, middle infrared), $\rho_{\mathrm{t}}{ }^{1}=$ $0.122 \pm 0.004$ (TM 1, blue) and $\rho_{\mathrm{t}}^{3}=0.082 \pm 0.005$ (TM 3, red),

The reflectance for the middle infrared was corrected atmospherically using the $6 \mathrm{~S}$ code considering an atmosphere with no aerosol, and obtaining that at the bottom of the atmosphere $\rho_{\mathrm{b}}^{7}$, $=0.100 \pm 0.006$ (TM 7, middle infrared). Next, by means of the equations 4 it was determined that at the bottom of the atmosphere $\rho_{b}^{1},=0.0233 \pm 0.0014$ (TM 1, blue) and $\rho_{b}^{3}$, $=0.050 \pm 0.003$ (TM 3, red). Then we proceeded to obtain the aerosol optical thickness. For this purpose, we elaborated a table by using the $6 \mathrm{~S}$ code. By interpolation of the table the result was $\tau_{1}=0.369 \pm 0.011$ and $\tau_{3}=0.37 \pm 0.02$. The small dispersion between both values shows that the aerosol and atmosphere models selected where suitable.

Afterwards, we corrected atmospherically the red and near infrared channels using the $6 \mathrm{~S}$ code. For this purpose, a table search procedure and subsequent lineal interpolation for each image pixel was implemented.

In order to analyse the effect of atmospheric correction on the thermal emissivity values, we used the sub-scenes A and B of Figure 2. They do not include urbanized areas or road links, and the existing water has been conveniently blacked out. One pixel identified as pure soil and other one of pure vegetation, both on the top and the bottom of the atmosphere reflectance images, have been located for each of the sub-scenes, using the values of the NDVI histogram. With these land and vegetation pixels, the reflectance in the red and near infrared has been measured, as well as the corresponding NDVI. Then we proceeded to calculate the proportion of vegetation and thermal emissivity using the equations (2) and (1) respectively.

TABLE I. VARIATION OF REFLECTANCE, NDVI, PV, EMISSIVITY AND TEMPERATURE WHEN USING ATMOSPHERICALLY CORRECTED REFLECTANCES IN THE EMISSIVITY ESTIMATION WITH VCM METHOD IN RELATION TO NONCORRECTED SCENES

\begin{tabular}{|c|c|}
\hline Magnitudes & Variation \\
\hline Red reflectance (TM 3) & $8 \%$ \\
Near infrared reflectance (TM 4) & $18 \%$ \\
NDVI & $15 \%$ \\
Pv & $58 \%$ \\
Emissivity & $0.4 \%$ \\
Temperature & $0.2 \mathrm{~K}$ \\
\hline
\end{tabular}

Table I allows to observe that, even though for the reflectances in the red and near infrared, the vegetation index and fractional vegetation cover increase, the mean thermal emissivity only increases $0.4 \%$. Nevertheless, in according to [1] this increase causes a mean systematic error of approximately $+0.2 \mathrm{~K}$ in the temperature value.

\section{CONCLUSIONS}

In this paper we have combined the $6 \mathrm{~S}$ and DDV methods in order to implement an operational atmospheric correction procedure for the effects of the emissivity calculations. The method has been applied to a Landsat TM sub-scene in the Tomelloso area (Ciudad Real, Spain). The vegetation index and proportion showed a substantial increase of their mean values when using atmospherically corrected reflectances values. Nevertheless, only a $0.4 \%$ increase has been detected in the emissivity. Nonetheless, this increase causes a systematic error in the temperature measure of approximately $+0.2 \mathrm{~K}$. 


\section{ACKNOWLEDGMENT}

The authors wish to express our gratitude to Dr. Eva M. Rubio and Dr. M. Mar Artiago of Castilla La Mancha University, for the Tomelloso image information. We are also grateful to Dr. Eric F. Vermote of Maryland University, for his explanations concerning to atmospheric correction.

\section{REFERENCES}

[1] BECKER, F., 1987, The impact of spectral emissivity on the measurement of land surface temperatures from a satellite, Int. J. Remote Sens. 8(10), 1509-1522.

[2] VALOR, E and CASELLES, V., 1996, Mapping land surface emissivity from NDVI: applications to European, African, and South American areas. Remote Sens. Environ., 57: 167-184.

[3] VAN DE GRIEND, A. A., and OWE, M., 1993, On the relationship between thermal emissivity and the normalized difference vegetation index for natural surfaces, Int. J. Remote Sens., 14: 1119-1131.

[4] SONG C., WOODCOCK C.E., SETO K.C., LENNEY M.P. and MACOMBER, S.A., 2001, Classification and change detection using Landsat TM data: when and how to correct atmospheric effects?, Remote Sens. Environ., 75: 230-244.

[5] BOLLE, H. J. and LANGER, I., 1991, Echival Field Experiment in a Desertification-Threatened Area (EFEDA). Field Experiment Plan. Meteorological Institute, Free University of Berlin, Germany.

[6] VERMOTE, E., TANRÉ, D., DEUZÉ, J.L., HERMAN, M. and MORCRETTE, J. J., 1997, Second simulation of the satellite signal in the solar spectrum, 6S: an overview. IEEE Trans. Geosci. Remote Sens., 35: 675-686.

[7] CASELlES, V. and LÓPEZ, M. J., 1989, An alternative simple approach to estimate atmospheric correction in multitemporal studies. Int. J. Remote Sens., 10: 1127-1134.
[8] HOLBEN, B.N., 1986, Characteristics of maximun-value composite images from temporal AVHRR data. Int. J. Remote Sens., 7: 1417-1434.

[9] PONS, X. and SOLÉ-SUGRAÑES, L. 1994. A simple radiometric correction model to improve automatic mapping of vegetation from multispectral satellite data, Remote Sens. Environ., 48: 191-204.

[10] LIANG S., FALLAH-ADL H., KALLURI S., JAJA J., KAUFMAN Y., and TOWNSHEND J., 1997, An operational atmospheric correction algorithm for Landsat Thematic Mapper imagery over land, J. Geophys. Res., 102: 173-186.

[11] TANRE, D., DESCHAMPS, P. Y., DEVAUX, C., and HERMAN, M., 1988, Estimation of Saharian aerosol optical thickness from blurring effects in Thematic Mapper data, J. Geophys. Res., 15.955-15.964.

[12] RUBiO, E., CASELlES, V., and BADENAS, C., 1997, Emissivity measurements of several soils and vegetation types in the 8-14 m waveband: Analysis of two field methods. Remote Sens. Environ., 59: 490-521.

[13] SALISBURY, J. W. and D'ARIA, D. M., 1992, Emissivity of terrestrial materials in the $8-14 \mu \mathrm{m}$ atmospheric window, Remote Sens. Environ., 42: 83-106.

[14] KAUFMAN, Y. J. and SENDRA, C., 1988, Algorithm for automatic corrections to visible and near-infrared satellite imagery, Int. J. Remote Sens., 9: 1357-1381.

[15] OUAIDRARI, H. and VERMOTE, E., 1999, Operational atmospheric correction of Landsat TM data. Remote Sens. Environ., 70: 4-15.

[16] KAUFMAN, Y. J., WALD, A.E., REMER, L.A., GAO, B.C., LI, R.R., and FLYNN, L., 1997, The MODIS $2.1 \mu \mathrm{m}$ channel - Correlation with visible reflectance for use in remote sensing of aerosol, IEEE Trans. Geosci. Remote Sens., 35: 675-686.

[17] ARTIGAO, M. M., RUBIO, E. M., and CASELLES, V., 2005, Actual evapotranspiration in a vineyard of Spain, Recent Research Developments in Thermal Remote Sensing, 135-155 (Research Signpost: Kerala). 